\title{
ANALISA KAVITASI TERHADAP POMPA THORISHIMA BERDASARKAN VARIASI TEMPERATUR DAN KETINGGIAN INSTALASI DEARATOR
}

\author{
Zulham Effendi, Siti Aisyah, dan Suhermansyah Pratama \\ STIPER Agrobisnis Perkebunan Medan \\ Email: zulham@stipap.ac.id
}

\begin{abstract}
ABSTRAK
Unjuk kerja pompa sentrifugal ditandai dengan besarnya efisiensi, head, dan kapasitas pompa tersebut apabila digunakan dengan daya yang sama. Untuk memperbaiki unjuk kerja tersebut, maka dibutuhkan penelitian dan kajian yang mendalam untuk mendapatkan karakteristik pompa sentrifugal yang diinginkan dalam mendistribusikan air ke deaerator dengan temperatur yang maksimal tanpa mengalami kavitasi. Penelitian ini bertujuan untuk mengetahui headloss serta proses kavitasi yang terjadi pada pipa di PKS Tebing Tinggi. Dari hasil analisis yang telah dilakukan maka telah diketahui total headloss yang terjadi pada sistem perpipaan ketinggian $6 \mathrm{~m}$ sebesar 2,8498 m, ketinggian $8 \mathrm{~m}$ sebesar 3,4648 m, ketinggian $10 \mathrm{~m}$ sebesar $4.0698 \mathrm{~m}$, ketinggian $12 \mathrm{~m}$ sebesar $4.6798 \mathrm{~m}$. Kemudian proses terjadi kavitasi pada sistem perpipaan hanya terjadi pada ketinggian $6 \mathrm{~m}$ pada temperatur $102^{\circ} \mathrm{C}$ $-105^{\circ} \mathrm{C}$ dan ketinggian $8 \mathrm{~m}$ terlihat pada temperatur $105^{\circ} \mathrm{C}$. Selanjutnya pada ketinggian 10 meter dan ketinggian 12 meter proses terjadinya kavitasi itu sudah tidak ada. Maka dari itu berdasarkan potensi yang telah diperhitungkan bahwa semakin tinggi instalasi deaerator kecil kemungkinan terjadinya kavitasi serta pada nilai efisiensi yang ideal terjadi pada ketinggian 10 meter dan 12 meter.

Kata kunci: deaerator; kavitasi; tinggi instalasi pipa
\end{abstract}

\section{PENDAHULUAN}

Pompa merupakan salah satu komponen yang paling penting dalam hal pendistribusian fluida (terutama air). Pada Pabrik Kelapa Sawit (PKS), pompa sangat berperan penting dalam mendistribusikan suatu fluida dari satu tempat menuju tempat lainnya. Pada pompa fluida, pompa sentrifugal memegang peranan yang amat penting karena penggunaannya paling banyak. Selain itu pompa sentrifugal memiliki efisiensi, head, dan kapasitas pompa yang besar apabila digunakan dengan daya yang sama. Pompa adalah mesin atau peralatan mekanis (kerja putar poros) yang digunakan untuk menaikkan cairan dari dataran rendah ke dataran tinggi atau untuk mengalirkan cairan dari daerah bertekanan rendah ke daerah yang bertekanan tinggi dan juga sebagai penguat laju aliran pada suatu sistem jaringan perpipaan (Sularso 2000). Hal ini dicapai dengan membuat suatu tekanan yang rendah pada sisi masuk (suction) dan tekanan yang tinggi pada sisi keluar (discharge) dari pompa. Pompa berfungsi untuk memindahkan zat cair dari tempat yang rendah ke tempat yang lebih tinggi. Disamping itu pompa juga digunakan untuk memindahkan zat cair dari tempat yang lebih tinggi ke tempat yang lebih rendah, misalnya pada sistem pemipaan yang panjang dan berbelok-belok, sehingga mempunyai tekanan hidrolik yang lebih tinggi (Dietzel, 1993). Kavitasi terjadi bila tekanan fluida pada saat memasuki pompa turun hingga di bawah tekanan uap jenuhnya (pada temperatur lingkungan), gelembung-gelembung uap kecil akan mulai terbentuk.

Faktor penyebab terjadinya kavitasi adalah : 1) Penguapan (Vaporization), dimana fluida menguap bila tekanannya menjadi sangat rendah atau temperaturnya menjadi sangat tinggi. Setiap pompa sentrifugal memerlukan head (tekanan) pada sisi isap untuk mencegah penguapan. Tekanan yang diperlukan ini, disiapkan oleh pabrik pembuat pompa dan dihitung berdasarkan asumsi bahwa air yang dipompakan adalah 'fresh water' pada suhu $68^{\circ} \mathrm{F}$, kejadian ini disebut Net Positive Suction Head Available (NPSHA). Karena ada pengurangan tekanan (head losses) pada sisi suction (karena adanya valve, elbow, reduser, dll ), maka perhitungan head total pada sisi suction dan biasa disebut Net Positive Suction Head is Required (NPSHR). Nilai keduanya mempengaruhi terjadinya penguapan, maka untuk mencegah penguapan, syaratnya adalah : NPSHA $-\mathrm{Vp} \geq$ NPSHR, dimana : Vp = Vapor pressure fluida yang dipompa. 2). Masuknya udara luar ke dalam sistem (Air Ingestion). Pompa sentrifugal hanya mampu mengendalikan $0.5 \%$ udara dari total volume. Lebih dari $6 \%$ udara, akibatnya bisa sangat berbahaya, dapat merusak komponen pompa. 3). Sirkulasi balik di dalam sistem (Internal Recirculation), kondisi ini dapat terlihat pada sudut terluar (leading edge) impeller, dekat 
dengan diameter luar, berputar balik ke bagian tengah kipas. 4). Pergolakan aliran (turbulence), dimana aliran fluida diinginkan pada kecepatan yang konstan. 5). Vane Passing Syndrome, dimana kerusakan akibat kavitasi jenis ini terjadi ketika diameter luar impeller lewat terlalu dekat dengan 'cutwater' pompa.

Deaerator adalah alat yang bekerja untuk membuang gas-gas yang terkandung dalam air ketel, sesudah melalui proses pemurnian air (water treatment). Selain itu deaerator juga berfungsi sebagai pemanas awal air pengisian ketel sebelum dimasukkan kedalam boiler. Deaerator bekerja berdasarkan sifat 26 dari oksigen yang kelarutannya pada air akan berkurang dengan adanya kenaikan suhu. Alat deaerator ini terdiri dari dua drum dimana drum yang lebih kecil merupakan tempat pemanasan pendahuluan dan pembuangan gas-gas dari bahan air ketel, sedangkan drum yang lebih besar adalah merupakan tempat penampungan bahan air ketel yang jatuh dari drum yang lebih kecil di atasnya. Pada drum yang lebih kecil terdapat spray nozzle yang berfungsi untuk menyemprot bahan air ketel menjadi butiran-butiran air halus agar proses pemanasan dan pembuangan gas- gas dari bahan air ketel lebih sempurna. Juga pada drum yang lebih kecil disediakan satu saluran vent agar gas-gas dapat terbuang (bersama steam) ke atmosfer.

Penggunaan pompa yang demikian luas dengan berbagai macam jenis dan bentuknya, sehingga menarik peneliti untuk melakukan penelitian tentang kavitasi dan efesiensi pompa thorishima (Eta $\mathrm{N}$ 65x50-315,1) berdasarkan variasi temperatur dan ketinggian instalasi daerator. Penelitian ini bertujuan untuk mengetahui headloss serta proses kavitasi yang terjadi pada pipa di PKS Tebing Tinggi.

\section{METODOLOGI PENELITIAN}

Penelitian ini dilaksanakan di salah satu Pabrik Kelapa Sawit (PKS) Tebing Tinggi, Sumatra Utara, selama 2 bulan yaitu pada bulan Maret sampai dengan Mei 2020. Alat yang digunakan pada penelitian ini (Gambar 1) yaitu feed water tank, deaerator dan instalasi perpipaan, pompa, elektromotor, manometer, dan thermometer. Sedangkan bahan yang digunakan berupa data pada pipa dan air. Spesifikasi pompa disajikan pada Tabel 1.

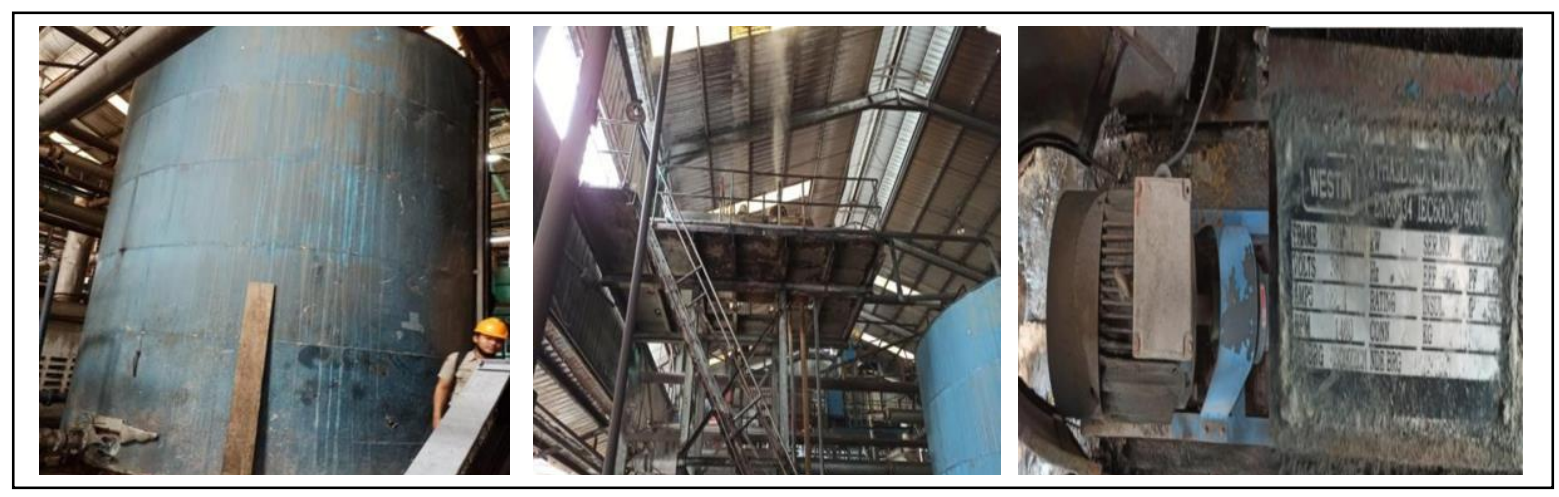

(a)

(b)

(c)

Gambar 1 a). Feed water tank PKS, b) Deaerator dan instalasi sistem perpipaan, c) Pompa deaerator PKS

Tabel 1. Spesifikasi Pompa PKS Tebing Tinggi

\begin{tabular}{lc}
\hline \multicolumn{1}{c}{ Merk } & Thorishima \\
\hline Type & ETA N $65 \times 50-315,1$ \\
Kapasitas & $25 \mathrm{~m}^{3} / \mathrm{jam}$ \\
Total head & $35 \mathrm{~m}$ \\
Putaran & $1450 / \mathrm{min}$ \\
Temperatur & $10-100{ }^{\circ} \mathrm{C}$ \\
Driver & $7,5 \mathrm{kw}$ \\
Tahun & 2005 \\
\hline
\end{tabular}




\section{A. Prosedur Penelitian}

Tahap pengumpulan data mengunakan tiga macam pendekatan yaitu:

a. Observasi, meliputi survey lapangan dan literature secara langsung terhadap objek yang akan di lapangan.

b. Wawancara, yang dilakukan kepada pimpinan perkebunan kelapa sawit dan pihak terkait dengan bertanya langsung mengenai data yang penulis perlukan.

c. Studi kepustakaan, untuk melengkapi data-data yang diperlukan maka penulis melakukan studi kepustakan untuk menambah bahan ilmiah yang ada hubungannya dengan rancangan ini.

Data diperoleh dengan mengoptimalkan temperatur pada deaerator untuk membantu mengurangi beban kerja boiler. Selain itu dilihat ketinggian yang ideal pada deaerator serta cara untuk meningkatkan kinerja pada mesin pompa agar lebih efisien dan efektif di PKS.

\section{B. Pengamatan dan Analisis Data}

Penelitian ini dilakukan dengan mengefisiensikan pompa variasikan temperatur $95-105^{\circ} \mathrm{C}$ serta menghubungkannya dengan variasi ketinggian deaerator $6 \mathrm{~m}, 8 \mathrm{~m}, 10 \mathrm{~m}$, dan $12 \mathrm{~m}$ yang berada pada salah satu PKS di Tebing Tinggi (Sumatera Utara, Medan). Adapun perhitungan yang dilakukan dalam penelitian ini adalah :

1. Perhitungan kecepatan aliran pada pipa, yang bertujuan untuk mengetahui debit atau kecepatan aliran yang melalui pipa hisap $\varnothing 3$ " dan pipa tekan $\varnothing 2$ ".

2. Perhitungan kerugian head akibat gesekan dalam pipa, yang bertujuan untuk mengetahui kerugian head akibat gesekan yang melalui pipa hisap $\emptyset 3$ " dan pipa tekan $\emptyset 2$ " serta menghitung kerugian head pada sambungan pipa elbow $90^{\circ}$ dengan menggunakan rumus berikut:

$h_{f}=f \times \frac{L}{d} \times \frac{v^{2}}{2 g}$

dimana: $\mathrm{hf}=$ kehilangan energy $(\mathrm{m}) ; \mathrm{f}=$ faktor gesekan, yang tergantung dari angka Reynolds (diagram Moody); $\mathrm{L}=$ panjang pipa $(\mathrm{m}), \mathrm{d}=$ diameter pipa $(\mathrm{m}), \mathrm{v}=$ kecepatan aliran fluida dalam pipa $(\mathrm{m} / \mathrm{s}) ; \mathrm{g}=$ gaya gravitasi

\section{HASIL DAN PEMBAHASAN}

Berdasarkan kondisi di pabrik kelapa sawit Tebing Tinggi, pompa yang digunakan adalah jenis pompa sentripugal (ETA-N 65x50-31_5.1) dengan ketinggian deaerator $8 \mathrm{~m}$. Pompa tersebut berfungsi untuk memindahkan air dari feed water tank menuju deaerator dengan temperatur $90^{\circ} \mathrm{C}$. Setelah terjadi proses pendistribusian air menuju deaerator, diharapkan air yang sudah masuk deaerator memiliki temperatur yang tinggi agar kadar oksigen yang terkandung di dalam air dapat terlepas yang berguna untuk mempermudah proses pemanasan boiler serta mencegah proses kavitasi pada pipa di pabrik kelapa sawit. Pada bagian deaerator diharapkan proses meminimalisirkan oksigen sangat optimal untuk memudahkan boiler dalam menghasilkan uap dan menghemat bahan bakar. Pada proses tersebut dibutuhkan temperatur air yang lebih tinggi karena dengan sifat pemanasan inilah faktor kelarutan oksigen menurun.

\section{A. Debit Pipa}

Pada Tabel 2 dapat dilihat bahwa kecepatan aliran (V) pada sisi isap dengan diameter $\emptyset 3^{\prime \prime}$ lebih kecil dibanding pada sisi tekan dengan diameter $\emptyset 2 "$, hal ini disebabkan karena unsur-unsur yang mengelilingi oksigen pada air yang berupa unsur nitrogen, flor, dan fosfor, sulfur dan klor jika berikatan dengan hidrogen akan menghasilkan gas pada temperatur dan tekanan normal sehingga kecepatan yang keluar pada sisi isap pipa yang besar akan menjadi sedikit (Ubaedillah, 2016).

Tabel 2. Hasil Perhitungan Debit, Kecepatan dan Bilangan Reynold (Re)

\begin{tabular}{ccccc}
\hline Pipa & Debit $(\mathrm{Q})\left(\mathrm{m}^{3} / \mathrm{s}\right)$ & Luas $(\mathrm{A})\left(\mathrm{m}^{2}\right)$ & Kecepatan $(\mathrm{V})(\mathrm{m} / \mathrm{s})$ & Bilangan Reynold $(\mathrm{Re})$ \\
\hline Isap $\emptyset 3^{\prime \prime}$ & 0,0069 & 0,004558 & 1,5138 & 353839 \\
Tekan $\emptyset 2^{\prime \prime}$ & 0,0069 & 0,002025 & 3,4074 & 530969 \\
\hline
\end{tabular}


Pada Tabel 3 terlihat bahwa nilai total mayor losses pada pipa isap $(\mathrm{H} f)$ yaitu 0,1128 , dimana tinggi tekan merupakan ketinggian fluida yang dibutuhkan agar dapat naik untuk memperoleh jumlah energi yang sama dengan yang dikandung dalam satu satuan bobot fluida pada kondisi yang sama. Nilai pipa total pipa isap dengan ketinggian $1 \mathrm{~m}$ sesuai dengan jumlah energi yang dibutuhkan (Ubaedillah 2016).

Tabel 3. Hasil Perhitungan Mayor Losses Pada Sisi Isap Ketinggian $1 \mathrm{~m}$

\begin{tabular}{|c|c|c|c|c|}
\hline No & Headloss (m) & $\frac{\text { Panjang (m) }}{\text { Jumlah (pcs) }}$ & $\begin{array}{c}f(\text { Kofisien } \\
\text { Gesek })\end{array}$ & $\mathrm{H} f$ Total $(m)$ \\
\hline 1 & Gesekan pada pipa (Ø3) & $1 \mathrm{~m}$ & $f=0.026$ & 0.0368 \\
\hline 2 & Gate valve & $1 \mathrm{pcs}$ & $f=0.34$ & 0.04 \\
\hline 3 & Belokan pipa (Elbow $\left.90^{\circ}\right)$ & $2 \mathrm{pcs}$ & $f=0.15$ & 0.036 \\
\hline \multicolumn{3}{|c|}{ Total } & & 0.1128 \\
\hline
\end{tabular}

Pada Tabel 4 terlihat bahwa nilai total mayor losses pada pipa tekan $(\mathrm{H} f)$ yaitu 3,4648. Nilai ini sesuai dengan persamaan Bernoulli, dimana untuk aplikasi pada instalasi pompa, persamaan Bernoulli dalam bentuk energi "head" terdiri dari empat head, antara lain head elevasi, head tekanan, head kecepatan, dan head kerugian (Tim Pertamina 2009).

Tabel 4. Hasil Perhitungan Mayor Losses pada Sisi Tekan Ketinggian $8 \mathrm{~m}$

\begin{tabular}{|c|c|c|c|c|}
\hline No & Headloss (m) & $\begin{array}{l}\text { Panjang (m) } \\
\text { Jumlah (pcs) }\end{array}$ & $F$ (Koefisien Gesek) & $\mathrm{H} f$ Total $(m)$ \\
\hline 1 & Gesekan pada pipa (Ø2) & $8 \mathrm{~m}$ & $f=0,026$ & 2,425 \\
\hline 2 & Gate valve & $1 \mathrm{pcs}$ & $f=0,37$ & 0,22 \\
\hline 3 & Belokan pipa (Elbow $\left.90^{\circ}\right)$ & 7 pcs & $f=0,17$ & 0,707 \\
\hline & & $\begin{array}{l}\text { Total } \\
\text { dloss Total }\end{array}$ & & $\begin{array}{c}3,352 \\
3,4648 \\
\end{array}$ \\
\hline
\end{tabular}

Tabel 5. Hasil Perhitungan Head Statis, Head total dan NPSH

\begin{tabular}{cccccccc}
\hline Temperatur $\left({ }^{\circ} \mathrm{C}\right)$ & $\mathrm{P}(\mathrm{bar})$ & $\mathrm{Hsp}(\mathrm{m})$ & $\mathrm{Hs}(\mathrm{m})$ & $\mathrm{Hf}(\mathrm{m})$ & $\mathrm{Hvp}(\mathrm{m})$ & Total NPSHa $(\mathrm{m})$ & Keterangan \\
\hline 90 & 0,7 & 10,3 & 7 & 3,46 & 7,21 & 6,63 & Tidak Kavitasi \\
\hline
\end{tabular}

Pada Tabel 5 terlihat bahwa temperatur $90^{\circ} \mathrm{C}$ kondisi tidak kavitasi hal ini disebabkan pada temperatur dan tekanan atmosfir akan menyebabkan tekanan pada air menguap (Ubaedillah 2016). Pada akhirnya hasil perhitungan di atas diperoleh nilai NPSHa dengan kondisi temperatur $90{ }^{\circ} \mathrm{C}$. Kondisi tidak kavitasi itu disebabkan karena temperatur air $90^{\circ} \mathrm{C}$ dengan nilai tekanan 0,7 bar. Selain itu tekanan pada permukaan air di dalam tangki deaerator yaitu $10,3 \mathrm{~m}$ serta perbedaan tinggi antara permukaan air yang diisap dengan pompa yaitu $7 \mathrm{~m}$ sehingga kehilangan tekanan akibat gesekan air di dalam pipa sebesar 3,46 m. Setelah dikalkulasikan pada temperatur dengan tekanan atmosfir maka diperoleh nilai tekanan air menguap padasetiap temperaturnya. Pada akhirnya hasil perhitungan di atas diperoleh nilai NPSHa dengan kondisi temperatur $90^{\circ} \mathrm{C}$. setelah dilakukan perhitungan didapat hasil perhitungan NPSHa > NPSHr, dimana nilai NPSHr yaitu 1,7 maka diketahui kondisi instalasi pompa deaerator ke boiler tidak terjadi kavitasi (Rosid dan Sumarjo 2017).

Tabel 6. Hasil Perhitungan Daya dan Efisiensi Pompa

\begin{tabular}{ccccccr}
\hline $\begin{array}{c}\text { Temperatur } \\
\left({ }^{\circ} \mathrm{C}\right)\end{array}$ & $\begin{array}{c}\text { Berat Jenis Air } \\
(\mathrm{\Upsilon})\left(\mathrm{kg} / \mathrm{m}^{3}\right)\end{array}$ & $\begin{array}{c}\text { Kapasitas } \\
(\mathrm{Q})\left(\mathrm{m}^{3} / \mathrm{min}\right)\end{array}$ & $\begin{array}{c}\text { Head Total } \\
(\mathrm{H})(\mathrm{m})\end{array}$ & $\begin{array}{c}\text { Daya Air } \\
(\mathrm{Pw})(\mathrm{Kw})\end{array}$ & $\begin{array}{c}\text { Daya Motor } \\
(\mathrm{P})(\mathrm{Kw})\end{array}$ & $\begin{array}{c}\text { Efisiensi } \\
(\mathrm{\eta})(\%)\end{array}$ \\
\hline 90 & 965.3 & 0.4166 & 11.05 & 4.44 & 11 & 40.40 \\
\hline
\end{tabular}

Besarnya energi yang secara efektif diterima oleh air pada temperatur $90^{\circ} \mathrm{C}$ dengan kapasitas $0,4166 \mathrm{~m}^{3} / \mathrm{min}$, berat jenis air $965.3 \mathrm{~kg} / \mathrm{m}^{3}$, dan pada head total pompa $11.05 \mathrm{~m}$ maka dapat diketahui nilai daya air sebesar $4,44 \mathrm{Kw}$ sehingga didapat nilai efisiensi pompa yaitu 40,40\%. Nilai sesuai 
dengan kapasitas yang dialirkan PKS ke pompa.

\section{B. Kofisien Pipa Berdasarkan Potensi Variasi Ketinggian Deaerator dan Temperature Air}

Pada objek yang tersedia di PKS Tebing Tinggi masih ada potensi yang perlu dikembangkan dengan spesifikasi pompa yang sama dan instalasi pipa isap yang sama. Perlu dilakukannya perhitungan variasi pipa tekan pada instalasi deaerator sepanjang 6 meter, 8 meter, 10 meter dan 12 meter dengan temperatur air $95^{\circ} \mathrm{C}$ sampai $105^{\circ} \mathrm{C}$ berdasarkan sifat fisik airnya. Hal ini dilakukan untuk melihat kondisi yang paling ideal dan paling optimal dalam memanaskan air.

\section{a. Ketinggian Dearator 6 meter}

Pada Tabel 7 terlihat bahwa nilai total mayor losses pada pipa tekan sepanjang 6 meter $(\mathrm{H} f)$ sebesar 2,737 $\mathrm{m}$ dan nilai dari sisi isap dan sisi tekan sebesar 2,8498 m. Nilai ini dinyatakan sebagai tidak kavitasi.

Tabel 7. Hasil Perhitungan Mayor Losses pada Sisi Tekan Ketinggian $6 \mathrm{~m}$

\begin{tabular}{|c|c|c|c|c|}
\hline No & Headloss (m) & $\begin{array}{l}\text { Panjang (m) } \\
\text { Jumlah (pcs) }\end{array}$ & $f$ (Kofisien Gesek) & $\mathrm{H} f$ Total $(m)$ \\
\hline 1 & Gesekan pada pipa (Ø2) & $6 \mathrm{~m}$ & $f=0.026$ & 1.81 \\
\hline 2 & Gate valve & $1 \mathrm{pcs}$ & $f=0.37$ & 0.22 \\
\hline 3 & Belokan pipa (Elbow $\left.90^{\circ}\right)$ & $7 \mathrm{pcs}$ & $f=0.17$ & 0.707 \\
\hline & \multicolumn{3}{|c|}{$\begin{array}{l}\text { Total } \\
\text { Headloss Total }\end{array}$} & $\begin{array}{c}2.737 \\
2.8498\end{array}$ \\
\hline
\end{tabular}

Berdasarkan Tabel 8, kondisi tidak kavitasi itu berada pada temperatur $95^{\circ} \mathrm{C}-101^{\circ} \mathrm{C}$ dengan tekanan pada permukaan air di dalam tanki deaerator sebesar $10,3 \mathrm{~m}$. Perbedaan tinggi antara permukaan air yang diisap dengan pompa yaitu $5 \mathrm{~m}$ dan kehilangan tekanan akibat gesekan air di dalam pipa yaitu $2,85 \mathrm{~m}$. Setelah dikalkulasikan pada masing- masing temperatur dengan tekanan atmosfir maka diperoleh nilai tekanan air menguap pada masing-masing temperaturnya. Pada akhirnya hasil perhitungan di atas diperoleh nilai NPSHa > NPSHr, dimana nilai NPSHr yaitu 1,7 maka diketahui kondisi instalasi pompa deaerator ke boiler tidak terjadi kavitasi (Ubaedillah 2017).

Kemudian proses terjadinya kavitasi terjadi pada temperatur $102^{\circ} \mathrm{C}-105^{\circ} \mathrm{C}$ dengan nilai tekanan pada permukaan air di dalam tanki deaerator yaitu $10,3 \mathrm{~m}$ dan perbedaan tinggi antara permukaan air yang diisap dengan pompa yaitu $5 \mathrm{~m}$ sehingga kehilangan tekanan akibat gesekan air di dalam pipa yaitu $2,85 \mathrm{~m}$.

Tabel 8. Hasil Perhitungan Head Statis, Head Total dan NPSH 6 m

\begin{tabular}{rrrrrrrl}
\hline $\begin{array}{c}\text { Temperatur } \\
\left({ }^{\circ} \mathrm{C}\right)\end{array}$ & $\mathrm{P}(\mathrm{bar})$ & $\begin{array}{c}\text { Hsp } \\
(\mathrm{m})\end{array}$ & Hs $(\mathrm{m})$ & $\begin{array}{c}\text { Hf } \\
(\mathrm{m})\end{array}$ & $\begin{array}{c}\text { Hvp } \\
(\mathrm{m})\end{array}$ & $\begin{array}{c}\text { Total } \\
\text { NPSHa }(\mathrm{m})\end{array}$ & Keterangan \\
\hline 95 & 0.84 & 10.3 & 5 & 2.85 & 8.65 & 3.80 & Tidak Kavitasi \\
96 & 0.87 & 10.3 & 5 & 2.85 & 8.96 & 3.49 & Tidak Kavitasi \\
97 & 0.9 & 10.3 & 5 & 2.85 & 9.27 & 3.18 & Tidak Kavitasi \\
98 & 0.94 & 10.3 & 5 & 2.85 & 9.68 & 2.77 & Tidak Kavitasi \\
99 & 0.97 & 10.3 & 5 & 2.85 & 9.99 & 2.46 & Tidak Kavitasi \\
100 & 1.01 & 10.3 & 5 & 2.85 & 10.40 & 2.05 & Tidak Kavitasi \\
101 & 1.04 & 10.3 & 5 & 2.85 & 10.71 & 1.74 & Tidak Kavitasi \\
102 & 1.08 & 10.3 & 5 & 2.85 & 11.12 & 1.33 & Kavitasi \\
103 & 1.12 & 10.3 & 5 & 2.85 & 11.54 & 0.91 & Kavitasi \\
104 & 1.16 & 10.3 & 5 & 2.85 & 11.95 & 0.50 & Kavitasi \\
105 & 1.2 & 10.3 & 5 & 2.85 & 12.36 & 0.09 & Kavitasi \\
\hline
\end{tabular}


Pada Tabel 9, besarnya energi yang secara efektif diterima oleh air pada temperatur $95^{\circ} \mathrm{C}$ $105^{\circ} \mathrm{C}$ dengan kapasitas $0,4166 \mathrm{~m}^{3} / \mathrm{min}$, berat jenis air terdapat pada masing-masing temperatur, dan pada head total pompa $8,43 \mathrm{~m}$.

Tabel 9. Hasil Perhitungan Daya dan Efisiensi Pompa $6 \mathrm{~m}$

\begin{tabular}{ccccccc}
\hline $\begin{array}{c}\text { Temperatur } \\
\left({ }^{\circ} \mathrm{C}\right)\end{array}$ & $\begin{array}{c}\text { Berat Jenis Air } \\
(\Upsilon)\left(\mathrm{kg} / \mathrm{m}^{3}\right)\end{array}$ & $\begin{array}{c}\text { Kapasitas } \\
(\mathrm{Q})\left(\mathrm{m}^{3} / \mathrm{min}\right)\end{array}$ & $\begin{array}{c}\text { Head Total } \\
(\mathrm{H})(\mathrm{m})\end{array}$ & $\begin{array}{c}\text { Daya Air } \\
(\mathrm{Pw})(\mathrm{Kw})\end{array}$ & $\begin{array}{c}\text { Daya Motor } \\
(\mathrm{P})(\mathrm{Kw})\end{array}$ & $\begin{array}{c}\text { Efisiensi } \\
(\eta)(\%)\end{array}$ \\
\hline 95 & 961.9 & 0.4166 & 8.43 & 3.38 & 11 & 30.71 \\
96 & 961.2 & 0.4166 & 8.43 & 3.38 & 11 & 30.69 \\
97 & 960.5 & 0.4166 & 8.43 & 3.37 & 11 & 30.67 \\
98 & 959.8 & 0.4166 & 8.43 & 3.37 & 11 & 30.64 \\
99 & 959.1 & 0.4166 & 8.43 & 3.37 & 11 & 30.62 \\
100 & 958.3 & 0.4166 & 8.43 & 3.37 & 11 & 30.60 \\
101 & 957.7 & 0.4166 & 8.43 & 3.36 & 11 & 30.58 \\
102 & 956.9 & 0.4166 & 8.43 & 3.36 & 11 & 30.55 \\
103 & 956.2 & 0.4166 & 8.43 & 3.36 & 11 & 30.53 \\
104 & 955.5 & 0.4166 & 8.43 & 3.36 & 11 & 30.51 \\
105 & 954.7 & 0.4166 & 8.43 & 3.35 & 11 & 30.48 \\
\hline
\end{tabular}

\section{b. Ketinggian Deaerator 8 meter}

Pada ketinggian 8 meter, hasil perhitungan mayor losses dapat dilihat pada proses terjadi kavitasi dan tidak terjadi kavitasi yang terdapat pada Tabel 10. Pada prinsip yang sama, terlihat pada temperatur $105^{\circ} \mathrm{C}$ telah terjadi kavitasi, dimana tekanan pada permukaan air di dalam tanki deaerator yaitu $10,3 \mathrm{~m}$, serta perbedaan tinggi antara permukaan air yang diisap dengan pompa yaitu $7 \mathrm{~m}$. Selanjutnya kehilangan tekanan akibat gesekan air di dalam pipa sebesar 3,46 m. Hasil perhitungan diperoleh nilai NPSHa < NPSHr, dimana nilai NPSHr yaitu 1,7 dan diketahui kondisi instalasi pompa deaerator ke boiler terjadi kavitasi.

Tabel 10. Hasil Perhitungan Head Statis, Head Total dan NPSH 8 m

\begin{tabular}{cccccccc}
\hline $\begin{array}{c}\text { Temperatur } \\
\left({ }^{\circ} \mathrm{C}\right)\end{array}$ & $\begin{array}{c}\mathrm{P} \\
(\mathrm{bar})\end{array}$ & $\begin{array}{c}\text { Hsp } \\
(\mathrm{m})\end{array}$ & $\begin{array}{c}\mathrm{Hs} \\
(\mathrm{m})\end{array}$ & $\begin{array}{c}\mathrm{Hf} \\
(\mathrm{m})\end{array}$ & $\begin{array}{c}\text { Hvp } \\
(\mathrm{m})\end{array}$ & $\begin{array}{c}\text { Total NPSHa } \\
(\mathrm{m})\end{array}$ & Keterangan \\
\hline 95 & 0.84 & 10.3 & 7 & 3.46 & 8.65 & 5.19 & Tidak Kavitasi \\
96 & 0.87 & 10.3 & 7 & 3.46 & 8.96 & 4.88 & Tidak Kavitasi \\
97 & 0.9 & 10.3 & 7 & 3.46 & 9.27 & 4.57 & Tidak Kavitasi \\
98 & 0.94 & 10.3 & 7 & 3.46 & 9.68 & 4.16 & Tidak Kavitasi \\
99 & 0.97 & 10.3 & 7 & 3.46 & 9.99 & 3.85 & Tidak Kavitasi \\
100 & 1.01 & 10.3 & 7 & 3.46 & 10.40 & 3.44 & Tidak Kavitasi \\
101 & 1.04 & 10.3 & 7 & 3.46 & 10.71 & 3.13 & Tidak Kavitasi \\
102 & 1.08 & 10.3 & 7 & 3.46 & 11.12 & 2.72 & Tidak Kavitasi \\
103 & 1.12 & 10.3 & 7 & 3.46 & 11.54 & 2.30 & Tidak Kavitasi \\
104 & 1.16 & 10.3 & 7 & 3.46 & 11.95 & 1.89 & Tidak Kavitasi \\
105 & 1.2 & 10.3 & 7 & 3.46 & 12.36 & 1.48 & Kavitasi \\
\hline
\end{tabular}

Kemudian, kondisi tidak kavitasi berada pada temperatur $95^{\circ} \mathrm{C}-104^{\circ} \mathrm{C}$ dengan nilai tekanan pada permukaan air di dalam tanki deaerator yaitu $10,3 \mathrm{~m}$ serta perbedaan tinggi antara permukaan air yang diisap dengan pompa yaitu $7 \mathrm{~m}$ dan kehilangan tekanan akibat gesekan air di dalam pipa yaitu 3,46 m. sehingga didapat hasil perhitungan di atas diperoleh nilai NPSHa > NPSHr, dimana nilai NPSHr yaitu 1,7 yang diketahui kondisi instalasi pompa deaerator ke boiler tidak terjadi kavitasi

Pada Tabel 11, besarnya energi yang secara efektif diterima oleh air pada temperatur $95^{\circ} \mathrm{C}$ $105^{\circ} \mathrm{C}$ dengan kapasitas $0,4166 \mathrm{~m}^{3} / \mathrm{min}$, berat jenis air terdapat pada masing-masing temperatur, dan pada head total pompa $11,05 \mathrm{~m}$. 
Tabel 11. Hasil Perhitungan Daya dan Efisiensi Pompa $8 \mathrm{~m}$

\begin{tabular}{ccccccc}
\hline $\begin{array}{c}\text { Temperatur } \\
\left({ }^{\circ} \mathrm{C}\right)\end{array}$ & $\begin{array}{c}\text { Berat Jenis Air } \\
(\mathrm{\Upsilon})\left(\mathrm{kg} / \mathrm{m}^{3}\right)\end{array}$ & $\begin{array}{c}\text { Kapasitas }(\mathrm{Q}) \\
\left(\mathrm{m}^{3} / \mathrm{min}\right)\end{array}$ & $\begin{array}{c}\text { Head Total } \\
(\mathrm{H})(\mathrm{m})\end{array}$ & $\begin{array}{c}\text { Daya Air } \\
(\mathrm{Pw})(\mathrm{Kw})\end{array}$ & $\begin{array}{c}\text { Daya Motor } \\
(\mathrm{P})(\mathrm{Kw})\end{array}$ & $\begin{array}{c}\text { Efisiensi } \\
(\mathrm{\eta})(\%)\end{array}$ \\
\hline 95 & 961.9 & 0.4166 & 11.05 & 4.43 & 11 & 40.25 \\
96 & 961.2 & 0.4166 & 11.05 & 4.42 & 11 & 40.23 \\
97 & 960.5 & 0.4166 & 11.05 & 4.42 & 11 & 40.20 \\
98 & 959.8 & 0.4166 & 11.05 & 4.42 & 11 & 40.17 \\
99 & 959.1 & 0.4166 & 11.05 & 4.42 & 11 & 40.14 \\
100 & 958.3 & 0.4166 & 11.05 & 4.41 & 11 & 40.10 \\
101 & 957.7 & 0.4166 & 11.05 & 4.41 & 11 & 40.08 \\
102 & 956.9 & 0.4166 & 11.05 & 4.41 & 11 & 40.05 \\
103 & 956.2 & 0.4166 & 11.05 & 4.40 & 11 & 40.02 \\
104 & 955.5 & 0.4166 & 11.05 & 4.40 & 11 & 39.99 \\
105 & 954.7 & 0.4166 & 11.05 & 4.39 & 11 & 39.95 \\
\hline
\end{tabular}

\section{c. Ketinggian Deaerator 10 Meter}

Pada Tabel 12 dapat dilihat bahwa nilai dari sisi isap dan sisi tekan sebesar 4,0698 m. Nilai yang diperoleh sesuai dengan perhitungan dengan menggunakan Hukum Bernoulli.

Tabel 12. Hasil Perhitungan Mayor Losses pada Sisi Tekan Ketinggian $10 \mathrm{~m}$

\begin{tabular}{|c|c|c|c|c|}
\hline No & Headloss (m) & $\begin{array}{c}\text { Panjang (m) } \\
\text { Jumlah (pcs) }\end{array}$ & $\begin{array}{c}f \text { (Kofisien } \\
\text { Gesek) }\end{array}$ & $\mathrm{H} f$ Total $(m)$ \\
\hline 1 & Gesekan pada pipa (Ø2) & $10 \mathrm{~m}$ & $f=0.026$ & 3.03 \\
\hline 2 & Gate valve & $1 \mathrm{pcs}$ & $f=0.37$ & 0.22 \\
\hline 3 & Belokan pipa (Elbow $\left.90^{\circ}\right)$ & $7 \mathrm{pcs}$ & $f=0.17$ & 0.707 \\
\hline \multicolumn{4}{|c|}{$\begin{array}{c}\text { Total } \\
\text { Headloss Total }\end{array}$} & $\begin{array}{c}3.957 \\
4.0698\end{array}$ \\
\hline
\end{tabular}

Tabel 13. Hasil Perhitungan Head Statis, Head Total dan NPSH $10 \mathrm{~m}$

\begin{tabular}{clllllcl}
\hline Temperatur $\left({ }^{\circ} \mathrm{C}\right)$ & $\mathrm{P}(\mathrm{bar})$ & \multicolumn{7}{l}{ Hsp $(\mathrm{m})$} & Hs $(\mathrm{m})$ & $\mathrm{Hf}(\mathrm{m})$ & Hvp $(\mathrm{m})$ & Total NPSHa $(\mathrm{m})$ & Keterangan \\
\hline 95 & 0.84 & 10.3 & 9 & 4.07 & 8.65 & 6.58 & Tidak Kavitasi \\
96 & 0.87 & 10.3 & 9 & 4.07 & 8.96 & 6.27 & Tidak Kavitasi \\
97 & 0.9 & 10.3 & 9 & 4.07 & 9.27 & 5.96 & Tidak Kavitasi \\
98 & 0.94 & 10.3 & 9 & 4.07 & 9.68 & 5.55 & Tidak Kavitasi \\
99 & 0.97 & 10.3 & 9 & 4.07 & 9.99 & 5.24 & Tidak Kavitasi \\
100 & 1.01 & 10.3 & 9 & 4.07 & 10.40 & 4.83 & Tidak Kavitasi \\
101 & 1.04 & 10.3 & 9 & 4.07 & 10.71 & 4.52 & Tidak Kavitasi \\
102 & 1.08 & 10.3 & 9 & 4.07 & 11.12 & 4.11 & Tidak Kavitasi \\
103 & 1.12 & 10.3 & 9 & 4.07 & 11.54 & 3.69 & Tidak Kavitasi \\
104 & 1.16 & 10.3 & 9 & 4.07 & 11.95 & 3.28 & Tidak Kavitasi \\
105 & 1.2 & 10.3 & 9 & 4.07 & 12.36 & 2.87 & Tidak Kavitasi \\
\hline
\end{tabular}

Pada Tabel 13, kondisi tidak kavitasi itu berada pada temperatur $95^{\circ} \mathrm{C}-105^{\circ} \mathrm{C}$ dengan nilai tekanan tekanan pada permukaan air di dalam tanki deaerator yaitu $10,3 \mathrm{~m}$ serta perbedaan tinggi antara permukaan air yang diisap dengan pompa sebesar $9 \mathrm{~m}$ dan kehilangan tekanan akibat gesekan air di dalam pipa yaitu 4,07 m. Hasil perhitungan diperoleh nilai NPSHa > NPSHr, dimana nilai NPSHr yaitu 1,7 maka diketahui kondisi instalasi pompa deaerator ke boiler tidak terjadi kavitasi.

Pada Tabel 14, dapat dilihat besarnya energi yang secara efektif diterima oleh air pada temperatur $95^{\circ} \mathrm{C}-105^{\circ} \mathrm{C}$ dengan kapasitas $0,4166 \mathrm{~m}^{3} / \mathrm{min}$, berat jenis air terdapat pada masingmasing temperatur, dan pada head total pompa 13,66 m maka dari itu dapat diketahui nilai daya air terdapat pada masing- masing temperaturnya. 


\begin{tabular}{|c|c|c|c|c|c|c|}
\hline Temperatur $\left({ }^{\circ} \mathrm{C}\right)$ & $\begin{array}{l}\text { Berat Jenis Air } \\
(\Upsilon)\left(\mathrm{kg} / \mathrm{m}^{3}\right)\end{array}$ & $\begin{array}{c}\text { Kapasitas } \\
\text { (Q) }\left(\mathrm{m}^{3} / \mathrm{min}\right)\end{array}$ & $\begin{array}{l}\text { Head Total } \\
(\mathrm{H})(\mathrm{m})\end{array}$ & $\begin{array}{l}\text { Daya Air } \\
(\mathrm{Pw})(\mathrm{Kw})\end{array}$ & $\begin{array}{l}\text { Daya Motor } \\
\text { (P) }(\mathrm{Kw})\end{array}$ & $\begin{array}{l}\text { Efisiensi } \\
(\eta)(\%)\end{array}$ \\
\hline 95 & 961.9 & 0.4166 & 13.66 & 5.47 & 11 & 49.76 \\
\hline 96 & 961.2 & 0.4166 & 13.66 & 5.47 & 11 & 49.73 \\
\hline 97 & 960.5 & 0.4166 & 13.66 & 5.47 & 11 & 49.69 \\
\hline 98 & 959.8 & 0.4166 & 13.66 & 5.46 & 11 & 49.65 \\
\hline 99 & 959.1 & 0.4166 & 13.66 & 5.46 & 11 & 49.62 \\
\hline 100 & 958.3 & 0.4166 & 13.66 & 5.45 & 11 & 49.58 \\
\hline 101 & 957.7 & 0.4166 & 13.66 & 5.45 & 11 & 49.55 \\
\hline 102 & 956.9 & 0.4166 & 13.66 & 5.45 & 11 & 49.50 \\
\hline 103 & 956.2 & 0.4166 & 13.66 & 5.44 & 11 & 49.47 \\
\hline 104 & 955.5 & 0.4166 & 13.66 & 5.44 & 11 & 49.43 \\
\hline 105 & 954.7 & 0.4166 & 13.66 & 5.43 & 11 & 49.39 \\
\hline
\end{tabular}

Berdasarkan Tabel 15 , kondisi tidak kavitasi itu berada pada temperatur $95^{\circ} \mathrm{C}-105^{\circ} \mathrm{C}$ dengan nilai tekanan masing-masing dapat dilihat pada tabel 2.1. Kemudian tekanan pada permukaan air di dalam tanki deaerator yaitu 10,3 m serta perbedaan tinggi antara permukaan air yang diisap dengan pompa yaitu $11 \mathrm{~m}$ dan kehilangan tekanan akibat gesekan air di dalam pipa yaitu 4,68 m. Setelah dikalkulasikan pada masing-masing temperatur dengan tekanan atmosfir maka diperoleh nilai tekanan air menguap pada masing-masing temperaturnya. Pada akhirnya hasil perhitungan di atas diperoleh nilai NPSHa dengan kondisi temperatur $95^{\circ} \mathrm{C}-105^{\circ} \mathrm{C}$. Karena hasil nilai perhitungan NPSHa > NPSHr, dimana nilai NPSHr yaitu 1,7 maka diketahui kondisi instalasi pompa deaerator ke boiler tidak terjadi kavitasi.

Tabel 15. Hasil Perhitungan Head Statis, Head Total Dan NPSH 12 m

\begin{tabular}{|c|c|c|c|c|c|c|c|}
\hline $\begin{array}{c}\text { Temperatur } \\
\left({ }^{\circ} \mathrm{C}\right)\end{array}$ & $\begin{array}{c}\mathrm{P} \\
\text { (bar) }\end{array}$ & $\begin{array}{l}\mathrm{Hsp} \\
(\mathrm{m})\end{array}$ & Hs (m) & $\mathrm{Hf}(\mathrm{m})$ & $\operatorname{Hvp}(m)$ & $\begin{array}{c}\text { Total NPSHa } \\
(\mathrm{m})\end{array}$ & Keterangan \\
\hline 95 & 0.84 & 10.3 & 11 & 4.68 & 8.65 & 7.97 & Tidak Kavitasi \\
\hline 96 & 0.87 & 10.3 & 11 & 4.68 & 8.96 & 7.66 & Tidak Kavitasi \\
\hline 97 & 0.9 & 10.3 & 11 & 4.68 & 9.27 & 7.35 & Tidak Kavitasi \\
\hline 98 & 0.94 & 10.3 & 11 & 4.68 & 9.68 & 6.94 & Tidak Kavitasi \\
\hline 99 & 0.97 & 10.3 & 11 & 4.68 & 9.99 & 6.63 & Tidak Kavitasi \\
\hline 100 & 1.01 & 10.3 & 11 & 4.68 & 10.40 & 6.22 & Tidak Kavitasi \\
\hline 101 & 1.04 & 10.3 & 11 & 4.68 & 10.71 & 5.91 & Tidak Kavitasi \\
\hline 102 & 1.08 & 10.3 & 11 & 4.68 & 11.12 & 5.50 & Tidak Kavitasi \\
\hline 103 & 1.12 & 10.3 & 11 & 4.68 & 11.54 & 5.08 & Tidak Kavitasi \\
\hline 104 & 1.16 & 10.3 & 11 & 4.68 & 11.95 & 4.67 & Tidak Kavitasi \\
\hline 105 & 1.2 & 10.3 & 11 & 4.68 & 12.36 & 4.26 & Tidak Kavitasi \\
\hline
\end{tabular}

Berdasarkan variasi temperatur dan variasi ketinggian instalasi deaerator, maka dapat dilihat beberapa hasil perbandingan yang terjadi, diantaranya yang paling signifikan berdasarkan temperaturnya adalah nilai NPSHa dan efisiensi dengan variasi ketinggian yang dapat dilihat pada Tabel 16.

Pada Tabel 16, dapat dilihat pada ketinggian 6 meter dengan temperatur $95{ }^{\circ} \mathrm{C}-105{ }^{\circ} \mathrm{C}$ masih ada yang terjadi kavitasi karena nilai NPSHa menunjukkan lebih rendah dari nilai NPSHr. Proses terjadinya kavitasi tersebut terdapat pada temperatur $102{ }^{\circ} \mathrm{C}-105^{\circ} \mathrm{C}$. Kemudian pada nilai efisiensi menunjukkan persentase yang masih rendah sekali. Pada ketinggian 8 meter dengan temperatur $95{ }^{\circ} \mathrm{C}$ $-105{ }^{\circ} \mathrm{C}$ masih ada yang terjadi kavitasi karena nilai NPSHa menunjukkan lebih rendah dari nilai NPSHr. Proses terjadinya kavitasi tersebut terdapat pada temperatur $105^{\circ} \mathrm{C}$. Kemudian pada nilai efisiensi menunjukkan persentase yang masih rendah. Pada prinsip yang sama dengan ketinggian 10 
meter dengan temperatur $95{ }^{\circ} \mathrm{C}-105{ }^{\circ} \mathrm{C}$ sudah tidak terjadi kavitasi. Hal ini karena nilai NPSHa menunjukkan lebih tinggi dari nilai NPSHr, serta pada nilai efisiensi menunjukkan persentasi yang cukup tinggi. Sedangkan pada prinsip yang sama dengan ketinggian 12 meter dengan temperatur 95 ${ }^{\circ} \mathrm{C}-105^{\circ} \mathrm{C}$ sudah tidak terjadi kavitasi. Hal ini karena nilai NPSHa menunjukkan lebih tinggi dari nilai NPSHr, serta pada nilai efisiensi menunjukkan persentase yang tinggi.

Tabel 16. Nilai NPSHa dan efisiensi pompa dengan variasi tinggi

\begin{tabular}{ccccccccc}
\hline \multirow{2}{*}{ Data } & \multicolumn{2}{c}{ Tinggi $6 \mathrm{~m}$} & \multicolumn{2}{c}{ Tinggi $8 \mathrm{~m}$} & \multicolumn{2}{c}{ Tinggi $10 \mathrm{~m}$} & \multicolumn{2}{c}{ Tinggi $12 \mathrm{~m}$} \\
\cline { 2 - 8 } & NPSHa $(\mathrm{m})$ & Efisiensi $(\%)$ & NPSHa $(\mathrm{m})$ & Efisiensi $(\%)$ & NPSHa $(\mathrm{m})$ & Efisiensi $(\%)$ & NPSHa $(\mathrm{m})$ & Efisiensi $(\%)$ \\
\hline $\mathrm{T} 95^{\circ} \mathrm{C}$ & 3.8 & 30.71 & 5.19 & 40.25 & 6.58 & 49.76 & 7.97 & 59.27 \\
$\mathrm{~T} 96{ }^{\circ} \mathrm{C}$ & 3.49 & 30.69 & 4.88 & 40.23 & 6.27 & 49.73 & 7.66 & 59.23 \\
$\mathrm{~T} 97{ }^{\circ} \mathrm{C}$ & 3.18 & 30.67 & 4.57 & 40.2 & 5.96 & 49.69 & 7.35 & 59.18 \\
$\mathrm{~T} 98^{\circ} \mathrm{C}$ & 2.77 & 30.64 & 4.16 & 40.17 & 5.55 & 49.65 & 6.94 & 59.14 \\
$\mathrm{~T} 99^{\circ} \mathrm{C}$ & 2.46 & 30.62 & 3.85 & 40.14 & 5.24 & 49.62 & 6.63 & 59.1 \\
$\mathrm{~T} 100{ }^{\circ} \mathrm{C}$ & 2.05 & 30.6 & 3.44 & 40.1 & 4.83 & 49.58 & 6.22 & 59.05 \\
$\mathrm{~T} 101{ }^{\circ} \mathrm{C}$ & 1.74 & 30.58 & 3.13 & 40.08 & 4.52 & 49.55 & 5.91 & 59.01 \\
$\mathrm{~T} 102{ }^{\circ} \mathrm{C}$ & 1.33 & 30.55 & 2.72 & 40.05 & 4.11 & 49.5 & 5.5 & 58.96 \\
$\mathrm{~T} 103{ }^{\circ} \mathrm{C}$ & 0.91 & 30.53 & 2.3 & 40.02 & 3.69 & 49.47 & 5.08 & 58.92 \\
$\mathrm{~T} 104{ }^{\circ} \mathrm{C}$ & 0.5 & 30.51 & 1.89 & 39.99 & 3.28 & 49.43 & 4.67 & 58.88 \\
$\mathrm{~T} 105{ }^{\circ} \mathrm{C}$ & 0.09 & 30.48 & 1.48 & 39.95 & 2.87 & 49.39 & 4.26 & 58.83 \\
\hline
\end{tabular}

Pada perbandingan di atas maka dapat diketahui bahwa pada ketinggian 10 meter dan ketinggian 12 meter proses terjadinya kavitasi itu sudah tidak ada. Berdasarkan potensi yang telah diperhitungkan bahwa semakin tinggi instalasi deaerator maka kecil kemungkinan terjadinya kavitasi sedangkan untuk nilai efisiensi yang ideal terjadi pada ketinggian 10 meter dan 12 meter. Hal ini terjadi karena semakin tinggi instalasi deaerator maka semakin besar nilai persentasenya.

\section{KESIMPULAN}

Berdasarkan hasil perhitungan dari sistem perpipaan air menuju tangki deaerator yang berada pada pabrik kelapa sawit maka dapat disimpulkan sebagai berikut :

1. Total headloss yang terjadi pada sistem perpipaan yang ada pada PKS di Tebing Tinggi dengan ketinggian $6 \mathrm{~m}$ sebesar 2,8498 m, ketinggian $8 \mathrm{~m}$ sebesar 3,4648 m, ketinggian $10 \mathrm{~m}$ sebesar 4,0698 m, ketinggian $12 \mathrm{~m}$ sebesar 4,6798 m.

2. Proses terjadi kavitasi pada sistem perpipaan hanya terjadi pada ketinggian $6 \mathrm{~m}$ pada temperatur 102 ${ }^{\circ} \mathrm{C}-105{ }^{\circ} \mathrm{C}$ dan ketinggian $8 \mathrm{~m}$ terlihat pada temperatur $105^{\circ} \mathrm{C}$.

3. Berdasarkan potensi, semakin tinggi instalasi deaerator maka akan kecil kemungkinan terjadinya kavitasi dan semakin besar nilai persentasenya.

4. Nilai efisiensi yang ideal terjadi pada ketinggian 10 meter dan 12 meter.

\section{DAFTAR PUSTAKA}

Bruce, M. R. \& Donald, F. Y., 1994. Fundamentals of fluid menchanies. Second Edition. John Wiley $\&$ Sons. Inc Toronto.

Cantona, P., Dwi, M. S. A., Abadi, C. S., \& Syujak M., 2019. Analisis head loss dan kavitasi dari rangkaian pompa sentrifugal ebara di PT. PBI. Prosiding Seminar Nasional Teknik Mesin Politeknik Negeri Jakarta, 87-93

Dietzel, F., 1996. Turbin pompa dan kompresor. Alih Bahasa Dakso Sriyono. Jakarta: Erlangga Fluid Mechanics CCFL 120D. Alternate Examinations: The University of Trinidad \& Tobago H. Curch, Agustin. 1986. Pompa dan Blower Sentrifugal. Jakarta: Erlangga.

Hutabarat, B., 2019. Analisis unjuk kerja pompa sentrifugal dengan variasi head. Medan: Universitas Medan Area. 
Kamiel, B. P., Nasaka D. A., Riyanta B., \& Asyaratul A., 2019. Deteksi kavitasi pada pompa sentrifugal menggunakan spektrum getaran dan spektrum envelope. Journal Semesta Teknika, 22 (1), 1-10, doi: 10.18196/st.221231.

Kamiel, B. P., \& Ramadhan, R. S., 2017. Pengaruh kecepatan operasi pompa sentrifugal terhadap sensitifitas metode deteksi fenomena kavitasi berbasis parameter statistik domain waktu. Jurnal Ilmiah Semesta Teknika. 20 (1), 51-66.

Karrasik, I. J., Krutzch W, Cincin \& Warren, F., 1978. Pump Handbook $2^{\text {nd }}$ edition. USA: Mc Graw Hill Company.

Lazarkiewics S., 1965. Impleller pump. Warszawa : Widawnicta Naukowo Techniczne

Nuarsa, Z. I. M., \& Sayoga, I. M. A., 2012. Analisa pengaruh variasi sudut sambungan belokan terhadap head losses aliran pipa. Jurnal Teknik Mesin, 2 (2), 25-33.

Pratama,R., 2020. Analisa pengaruh konsumsi bahan bakar terhadap penghematan daya ditinjau dari eksergi pabrik kelapa sawit. Sekolah Tinggi Ilmu Pertanian Agrobisnis Perkebunan. Medan.

Puspawan, A., Nuramal, A., \& Suandi, A., 2016. Analysis of headloss and effeciency Of UGA-301AB type-centryfugal pump from cooling tower instalation to dust chamber un Urea P-IV maintenance division (Case Study In PT. Pupuk Sriwidjaja, Palembang City, South Sumatera Province). Jurnal Teknosia, II (12). 235-244.

Rosid dan Sumarjo, J., 2017. Analisa simulasi kerusakan impeller pada pompa sentrifugal akibat kavitasi. Jurnal Mesin Teknologi (SINTEK Jurnal). 11 (2). 12-25.

Sari, A. P., 2012. Simulasi pengaruh NPSH terhadap terbentuknya kavitasi pada pompa sentrifugal dengan menggunakan program komputer computational fluid dyanamic fluent. Medan: Universitas Sumatera Utara.

Stepanoff, A. J., 1957. Centrifugal and axial flow pumps : Theory, design, and application. New York: Wiley.

Sularso., 2000. Pompa dan kompresor. Jakarta : Pradaya Paramita.

Tardia L. 2019. Pompa sentrifugal. Jilid 1. Bandung : ITB Press

Tim Pertamina, 2009. Modul expertest Centryfugal Pumping Unit (CPU). Jakarta: Erlangga.

Ubaedilah. 2016. Analisa kebutuhan jenis dan spesifikasi pompa untuk suplai air bersih di gedung kantin berlantai 3 PT. Astra Daihatsu Motor. Jurnal Teknik Mesin (JTM). 05 (3). 346-355.

Wijianto dan Effendy, M., 2010. Aplikasi response getaran untuk menganalisi fenomena kavitasi pada instalasi pompa sentrifugal. Jurnal Penelitian Sains \& Teknologi. 11 (2). 191-206. 